\title{
023 PP INVOLVING PATIENTS AND CARERS IN RESEARCH: THE EXPERIENCE OF OLDER PEOPLE IN THE SHARED DECISION-MAKING PROCESS IN ADVANCED KIDNEY CARE $^{\mathrm{a}}$
}

N Thomas, ${ }_{1}{ }^{\text {* }} \mathrm{K}$ Jenkins, ${ }^{2}$ S Datta, ${ }^{3}$ R Endacott, ${ }^{3}$ J Kent, ${ }^{2}$ B McManus, ${ }^{3}$ R Moodley ${ }_{1}{ }^{3}$ B Murray, ${ }^{2}$ B Gracey ${ }^{3}$. ${ }^{1}$ Department of Adult Nursing and Midwifery, School of Health and Social Care, London South Bank University, UK; ${ }^{2}$ East Kent Hospitals NHS Foundation Trust, UK; ${ }^{3}$ Barts Health NHS Trust, UK

10.1136/bmjopen-2017-016492.41

Introduction: The aim of this qualitative study was to a) involve patients and carers in the research process and b) to understand the experiences of shared decision-making (SDM) in older people (over 70 years) in two National Health Service (NHS) Trusts.

Methods: A patient and carer group (PCG) were involved in writing the research proposal, developing interview questions, undertaking interviews and being involved in data analysis and dissemination of the findings.

The PCG members undertook volunteer and research training. The PCG undertook the interviews lasting 10-45 minutes with 29 people who had commenced dialysis (or had made a decision not to have dialysis) within the past six months. Interview data were then transcribed and analysed.

We also evaluated the benefits of involving patients and carers in the research process by a focus group with the PCG.

Results: 21 men and 7 women were interviewed. Their mean age was 77.4 years.

Overall the majority of patients were satisfied with the amount of information although some identified that the quality of the information could be improved i.e. more explanation of how daily living can be affected by dialysis.

The focus group with the six PCG members identified 3 themes: Experience of Interviewing; Personal Gain and Feeling Valued.

Conclusion: Our study is innovative because patients and carers have been involved in every stage of the research process. Our study has identified one potential way to measure impact of co-production on research process.

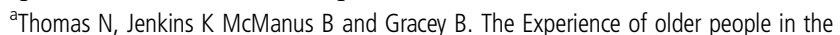
shared decision-making process in advanced kidney care. BioMed Research International 2016; Article ID 7859725: vol. 2016, Article ID 7859725, 8 pages. doi:10.1155/2016/ 7859725 